Review Article

\title{
Association of Depression/Anxiety Symptoms with Neck Pain: A Systematic Review and Meta-Analysis of Literature in China
}

\author{
Fushui Liu $\mathbb{D}^{1},{ }^{1}$ Ting Fang $\left(\mathbb{D},{ }^{1}\right.$ Fanyuan Zhou, ${ }^{1}$ Meimei Zhao ${ }^{\mathbb{D}},{ }^{1}$ Mei Chen $\left(\mathbb{D},{ }^{1}\right.$ Jianyu You, \\ Yuli Jin, ${ }^{1}$ Jinmei Xie, ${ }^{1}$ and Zhongyong Liu $\mathbb{\circledR}^{2}$ \\ ${ }^{1}$ School of Moxibustion, Jiangxi University of Traditional Chinese Medicine, Nanchang, China \\ ${ }^{2}$ College of Clinical Medicine, Jiangxi University of Traditional Chinese Medicine, Nanchang, China \\ Correspondence should be addressed to Zhongyong Liu; lzyongmail@163.com
}

Received 20 May 2018; Revised 16 July 2018; Accepted 9 August 2018; Published 25 September 2018

Academic Editor: Panagiotis Zis

Copyright (c) 2018 Fushui Liu et al. This is an open access article distributed under the Creative Commons Attribution License, which permits unrestricted use, distribution, and reproduction in any medium, provided the original work is properly cited.

Background. Due to its high morbidity and prevalence, the potential relationships of depression/anxiety symptoms in neck pain (NP) are not well demonstrated. Objectives. This study aimed to conduct a comprehensive estimation of controlled trials of psychological problems and to test hypotheses concerning whether NP was statistically relative to anxiety/depression symptoms. Methods. Chinese literature databases such as the China National Knowledge Infrastructure (CNKI), VIP Information (VIP), Chinese Biomedicine (CBM), and Wanfang Data (WANFANG) were scientifically searched for reports published until February 5, 2018. Controlled trials incorporating NP patients with anxiety/depression versus healthy people were contained. Two researchers screened each article and extracted data, respectively, and blinded to the findings of each other. Meta-analysis was conducted by the Cochrane Collaboration's RevMan 5.3 and Stata 14.0 (Stata Corp LP, USA) software. Results. We identified 13 eligible studies involving 2339 patients and 3290 healthy people. Compared with healthy control participants, the findings indicated that depression/anxiety symptoms were more common or severe in NP patients (respectively, $\mathrm{SMD}=0.89 ; 95 \% \mathrm{CI}=$ $(0.58,1.20) ; P<0.01$ and SMD $=0.92 ; 95 \% \mathrm{CI}=(0.65,1.20)$; and $P<0.01)$, results from the pooled data demonstrated no statistical significance between depression/anxiety symptoms and gender in NP patients (resp., $\mathrm{SMD}=0.16 ; 95 \% \mathrm{CI}=(-0.18,0.51) ; P=0.35$ and $\mathrm{SMD}=-0.08 ; 95 \% \mathrm{CI}=(-0.42,0.27)$; and $P=0.67)$, and the combined data of the incidence of depression or anxiety symptoms revealed significant difference between NP patients and healthy persons (resp., $\mathrm{RR}=4.81 ; 95 \% \mathrm{CI}=(3.30,7.01) ; P<0.01$ and $\mathrm{RR}=3.29 ; 95 \% \mathrm{CI}=(2.16,5.00)$; and $P<0.01)$. In addition, we did not find articles that met the inclusion criteria, which compared NP patients with other physical illnesses in terms of anxiety/depression symptoms. Conclusions. This meta-analysis suggests that anxiety/depression symptoms are associated with high morbidity in NP patients. We consider these reports support the viewpoint that nonspecific mechanisms mediate mental disturbances in NP. This study may have clinical value for NP, offering an underlying target for the prevention and treatment of anxiety/depression.

\section{Introduction}

Neck pain (NP) has become a common public health problem all over the world, with a high rate of disability, presents a negative impact on the health and quality of life in people, and exerts great pressure on individuals, families, health systems, and social economy [1-3]. Reportedly, NP was ranked the fourth leading cause of disability next to ischemic heart disease, cerebrovascular disease, and lower respiratory infection, with an annual prevalence rate exceeding $30 \%[4,5]$. In 2005, over a third of a billion had experienced neck pain more than 3 months of duration $[4,5]$. Preliminary statistics showed that the incidence of NP in China ranged between 3.8\% and $17.6 \%$, and it affected nearly $15 \%$ of the global population $[6,7]$. NP has obvious financial problems and the annual economic losses caused by NP are as high as $\$ 5$ billion in America, while it can reach $\$ 800$ million just for the treatment cost per year in China [6]. The prevention and treatment of NP has attracted the wide attention of people from all walks of life and has important practical significance for the study of NP.

The clinical symptoms of NP are complicated, which mainly include neck, shoulder and back pain, stiffness and 
weakness of upper limbs, numbness of fingers, dizziness, nausea, vomiting, and even blurred vision [8]. According to its clinical symptoms, it is divided into three syndromes, namely, cervical radiculopathy, cervical myelopathy, and axial neck pain [9]. By contrast, it contains seven types in China, including neck type, nerve root type, vertebral artery type, sympathetic type, spinal cord type, mixed type, and other type (mainly include esophageal compression type) [10]. The clinical diagnosis of NP is established on the basis of the identification of positive symptoms via diagnostic criteria and the exclusion of organic illness, for instance, unexplained dizziness and numbness [10]. Treatment for NP mainly depends on lifestyle intervention, medications, and physical therapies [11].

Research has found that mental health disorders are always connected with physical illness $[12,13]$ and is also more common in developing than developed countries [14]. What is particularly exciting here is the abundant description of depression/anxiety symptoms in NP. However, scholars differ in opinions on the nature of their relationships $[15,16]$. In short, at present, it exists two opposing schools of thought: one considers that NP may be tied closely to depression/anxiety through some pathogenesis and the other considers the associations between NP and mental disorders as nonspecific or chance events.

Despite plentiful descriptions have been reported about mental disturbs in NP patients, no systematic evaluation of the relationship between NP and depression/anxiety symptoms has been found. This article is to systematically review prospective cohort or case-control studies and investigate the association between NP and anxiety/depression symptoms. We completed the quality assessment of included studies to analyze any inconsistencies in data. The research questions are (1) whether depression/anxiety symptoms are more common or serious in NP patients than in healthy people or patients with other medical diseases? and (2) does depression/anxiety symptoms differ from gender in NP patients?

\section{Methods}

2.1. Search Strategy. According to Cochrane Reviews' Handbook, we developed a study protocol for this systematic review and meta-analysis [17]. Electronic searches were systematically performed in CNKI, VIP, CBM, and WANFANG databases up to February 5, 2018, by two authors (Ting Fang and Mei Chen). Medical subject headings $(\mathrm{MeSH})$ terms relevant to neck pain, anxiety, and depression was utilized in the search, and the same terms in Chinese databases. Then, we browsed the abstracts and full-text articles, respectively, and picked the eligible studies in line with the inclusion criteria. Additionally, we also manually searched the relevant lists of all eligible studies to identify further potential studies and contacted reference authors for additional data if necessary.

2.2. Criteria for Selecting Articles. Inclusion criteria include (1) prospective cohort or case-control studies that concerned anxiety/depression symptoms measured at baseline and their relationship with neck pain; (2) population-based studies that have compared a group of persons with neck pain with another group of either healthy persons or persons with other medical illness; (3) studies that evaluated depression and anxiety symptoms via validated psychometric testings or a structured clinical interview; (4) people diagnosed with neck pain utilizing a certain diagnostic criterion and patients' gender, age, the source of the case, and duration of illness were not limited; and (5) studies must have provided reasonable data for estimating effect size and confidence intervals.

Exclusion criteria include duplicate studies, animal experiments, no clear diagnostic criteria for NP, the measures of anxiety/depression symptoms were not standardized, studies that included treatment measures; and studies that only included NP patients as a subgroup of a large sample and not compared, respectively, from the other participants.

2.3. Data Extraction. Data were independently extracted from the eligible studies by two authors (Ting Fang and Mei Chen) and cross checked. Any discrepancies were discussed among Fushui Liu, Meimei Zhao, and Fanyuan Zhou. The key information was collected systematically using a predefined Excel template. It mainly included first author, year of publication, case source, baseline characteristics for participants (age, sex, and number of participants), diagnostic criteria of NP, assessment standards of depression and anxiety symptoms, and outcome assessments. Where possible, we contacted the first author for clarifying the ambiguous information that provided in some studies.

2.4. Quality Assessment. For detecting bias of included studies, the methodological quality was assessed according to a validated rating scale [18], which was used in psychiatric case-control studies. For this meta-analysis, we regulated this scale and researched selection bias of cases (seven items), selection of bias of controls (six items), and information bias (one item). The quality assessments were completed independently by two reviewers (Ting Fang and Mei Chen). Disagreements would be settled by discussing and analyzing between reviewers.

2.5. Data Analysis. We used RevMan 5.3 statistical software (the Nordic Cochrane Centre, Copenhagen; the Cochrane Collaboration, 2014) for meta-analysis. We defined $P \leq 0.05$ as statistically significant between studies. We calculated combined risk ratio (RR) with $95 \%$ confidence intervals (CI) for the categorical data; as continuous variables, we estimated combined standard mean difference (SMD) with $95 \%$ CI. The studies' heterogeneity was evaluated by the chisquare test and Higgins $I^{2}$ test, and when $I^{2} \leq 50 \%$ and $P \geq 0.10$, the fixed effect model was used or else the random effect model was applied.

2.6. Ethical Statement. All analyses were based on previously published studies, and so ethical approval was superfluous. 


\section{Results}

3.1. Search Results. Totally, 378 potential literature citations were initially obtained through database examinations. We removed 164 duplicates with EndNote software. 78 articles were ruled out through scanning the title and abstracts. And 118 articles were eliminated according to the exclusion and inclusion criteria. In the rest 18 articles, 3 of them did not compare with healthy people or patients with other medical disease, 2 studies failed to have assessment standards of depression and anxiety symptoms, and 13 eligible articles $[7,19-30]$ were included finally. The whole selection process is shown in Figure 1.

3.2. Basic Characteristics of Eligible Studies. The eligible studies were published between 2002 and 2017 in China, and 2339 patients and 3290 healthy controls were included. In these studies, regarding the source of cases, three studies $[7,22,24]$ were multiple-center controlled trials, two studies $[19,26]$ were ambiguous, and the remaining studies were single-center controlled trials. Also, they were all completed in outpatients and inpatients, except one [29] which was completed in college students. As for the source of cases in control groups, seven groups [7, 19, 20, 25-28] were from domestic normal population, and the others were healthy people.

NP was diagnosed in 4 studies $[22,25,29,30]$ using the diagnostic criteria acknowledged in China, and the others used self-rating criteria which were validated and reliable. As for the diagnostic criteria of depression and anxiety symptoms, all the studies reported validated scale. Seven studies [7, 19-21, 23, 25, 26] utilized the symptom check list90 (SCL-90), and 1 study [24] used the symptom check list290 (SCL-290) to assess depression and anxiety symptoms levels; among them, one study [19] also used the state-trait anxiety inventory (STAI). One study [30] utilized generalized anxiety disorder-7 (GAD-7) and patient health questionnaire-9 (PHQ-9) as the evaluation standard, 4 studies $[22,24,27,28]$ utilized self-rating depression scale (SDS), 2 studies [24, 27] used self-rating depression scale (SAS), and the criteria in the last one [29] were unclear. Table 1 shows the key characteristics of the included studies: study design, sample sizes, design, mean ages, diagnosis criteria for NP, and scales utilized for assessments of the levels of anxiety and depression.

3.3. Quality Assessment. Table 2 reports the methodological quality of the included studies. The clinical setting used for recruitment was frequently reported eligible information, so were the inclusion/exclusion criteria for cases. As for controls, one item concerning the using of students or employees of the research institution was always rated as "no," indicating good methodological practice. Few studies provided sufficient information about the using of advertising for recruitment. The rest questionnaire items for cases and controls were poorly described. Approximately half studies could not offer enough information on whether the investigators were "masked" or not.
3.4. Depression/Anxiety Symptoms Levels in NP Patients: Continuous. Depression and anxiety scores were, respectively, achieved in 13 and 10 studies that included SCL score and other depression rating scores. Data extracted from both reported significantly heterogeneity in the consistency of study results (respectively, $I^{2}=97 \%, P<0.01$, and $\left.I^{2}=94 \%, P<0.01\right)$, and the random effects model was applied. Overall, the depression and anxiety symptoms' scores were distinctly higher in NP patients compared to healthy control groups (resp., $\mathrm{SMD}=0.89 ; 95 \% \mathrm{CI}=(0.58,1.20)$; $P<0.01$ and $\mathrm{SMD}=0.92 ; 95 \% \mathrm{CI}=(0.65,1.20) ; P<0.01)$ (Figures 2 and 3 ).

3.5. Relationship between Anxiety/Depression Symptoms and Gender in NP Patients: Continuous. Only 2 studies [25, 30] reported the relationship between depression/anxiety scores and gender in NP patients. No heterogeneity exist in this analysis, and the fixed effects model was used. The overall results demonstrated no significant difference (resp., $\mathrm{SMD}=0.16 ; \quad 95 \% \quad \mathrm{CI}=(-0.18, \quad 0.51) ; \quad P=0.35 \quad$ and $\mathrm{SMD}=-0.08 ; 95 \% \mathrm{CI}=(-0.42,0.27) ; P=0.67)$ (Figure 4$)$.

3.6. The Incidence of Depression/Anxiety Symptoms in NP Patients: Categorical. 5 studies [22, 24, 27, 28, 30] provided categorical data for depression and anxiety, but only 2 of them $[22,24]$ presented categorical data in detail. The combined data revealed significant difference between NP patients and healthy persons, indicated that depression and anxiety were closely linked to NP patients (resp., $\mathrm{RR}=4.81$; $95 \% \mathrm{CI}=(3.30,7.01) ; P<0.01$ and $\mathrm{RR}=3.29 ; 95 \% \mathrm{CI}=(2.16$, 5.00); $P<0.01$ ) (Figure 5).

3.7. Sensitivity Analysis for Continuous Data. We completed the same meta-analysis for depression symptoms level in NP patients excluding 6 studies [22, 24, 27-30] whose psychiatric diagnostics were distinctly different from the remaining studies. The level of depression symptoms of NP patients was still higher than healthy control groups $(\mathrm{SMD}=0.52 ; 95 \%$ $\mathrm{CI}=(0.45,0.58) ; P<0.01)$. More importantly, the $I^{2}$ showed no heterogeneity between studies (I2 $=0 \%, P=0.59$ ). We also conducted the same meta-analysis for anxiety level in NP patients excluding 3 studies [24, 27, 30], as the psychiatric diagnostics were different from the remaining studies. The $I^{2}$ drops from 95 to $44 \%, P=0.10$, and the level of anxiety remained practically stable $(\mathrm{SMD}=0.73 ; 95 \%$ $\mathrm{CI}=(0.62,0.84) ; P<0.01)$. Totally, our different sensitivity analyses presented similar findings and indicated that the different psychiatric diagnostic criteria resulted high risk for the results.

\section{Discussion}

In this study, we identified 13 eligible studies involving 2339 patients and 3290 healthy people that intended to evaluate possible links between NP and mental disorders. According to our findings, compared to healthy control groups, the depression and anxiety symptoms scores were distinctly 


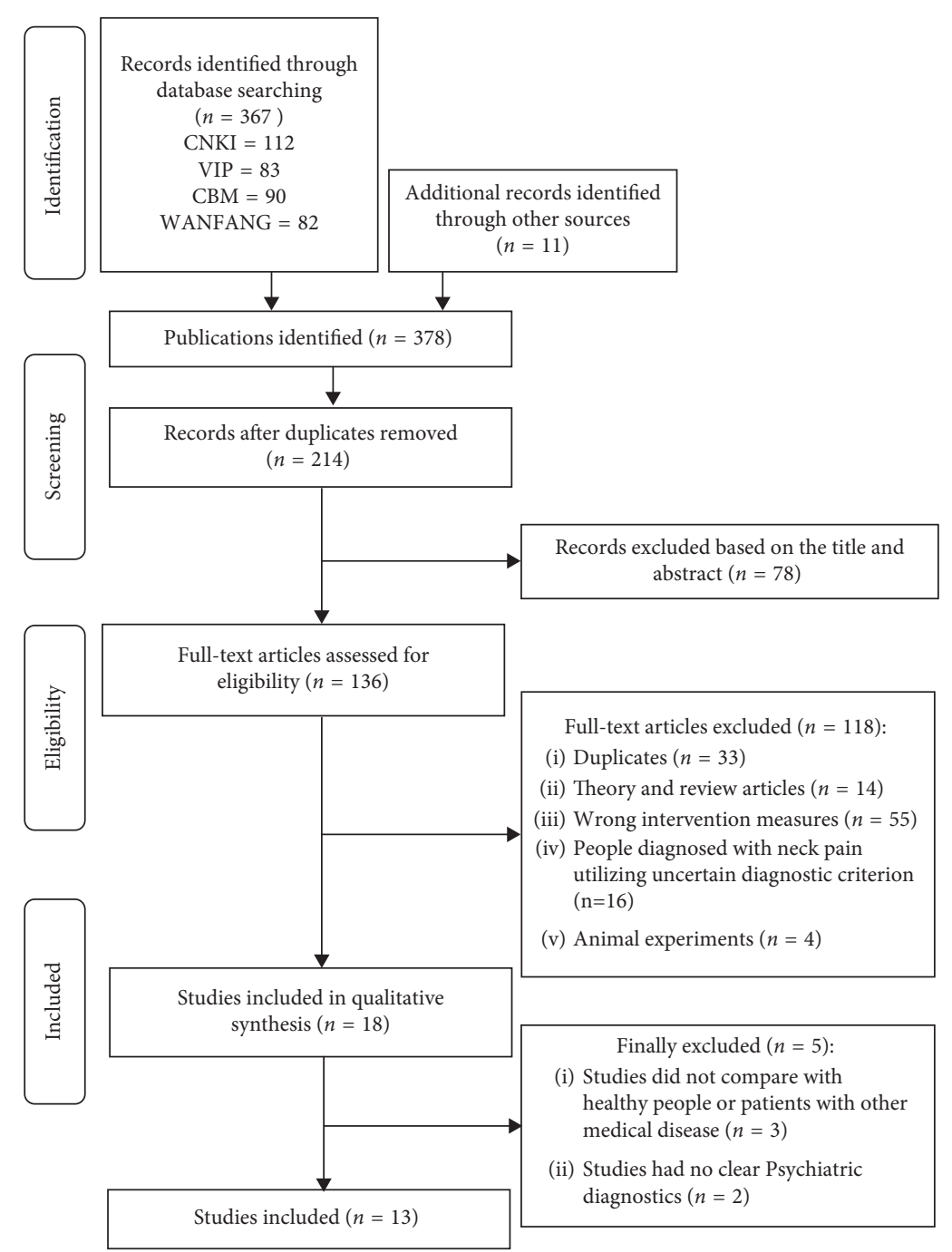

FIgURE 1: Flow diagram outlining the selection of studies for the review.

higher in NP patients. However, there was no significant difference between depression/anxiety symptoms and gender in NP patients. And we failed to obtain case reports to confirm whether NP patients differ from other chronic diseases in terms of anxiety and depression symptoms. But we found articles from PubMed which testified significant difference between NP patients and other chronic physical illnesses in terms of anxiety and depression symptoms $[31,32]$, and this conclusion deserved further exploration in future. Also, this study suggested that the morbidity of depression and anxiety symptoms was higher in NP patients. Wen and Liu [28] reported that the morbidity of depression symptoms in 336 cases of NP patients was $36.31 \%$, Huang et al. [27] found that incidence of anxiety and depression symptoms in $38 \mathrm{NP}$ patients was $60.53 \%$ and $92.11 \%$, respectively, while it was $77 \%$ and $84 \%$, respectively, in Sun's survey of $100 \mathrm{NP}$ patients [30].

Neck pain is a common and frequently occurring disease with complicated clinical etiology, which is mainly related to people's bad living habits, such as long-term head bending posture. It is easy to relapse and lasts for a long time [33].
Long-term chronic pain has a profound impact on patients' mental health, and they are prone to negative emotions such as anxiety and depression, which seriously affect patients' quality of life. Reportedly, the longer the chronic pain lasts, the more severe it becomes and the more anxious or depressive it becomes [34]. Meanwhile, anxiety and depression can also promote psychological responses to chronic pain [34].

Some authors investigated the effects of depression and anxiety symptoms in NP patients and found NP and poor quality of life were two factors leading to depression and anxiety [35]. Instead, Galbusera and Gorter reported depression and anxiety symptoms were two major factors affecting the quality of life in patients with musculoskeletal pain $[36,37]$. Relatively, few were currently known about causal mechanisms for depression and anxiety symptoms in NP patients. Different mechanisms perhaps could explain the relationship between pain and anxiety from different aspects of biology, psychology, and sociology [38]. Functional imaging studies showed the affective processing area of brain in patients with anxiety and depression symptoms 
TABLE 1: Summary of studies included in the meta-analyses on anxiety and depression in NP.

\begin{tabular}{|c|c|c|c|c|c|c|}
\hline Study & $\begin{array}{l}\text { Sample } \\
\text { sizes }\end{array}$ & Design & $\begin{array}{c}\text { Group } \\
\text { comparison }\end{array}$ & Mean age & NP diagnostics & $\begin{array}{l}\text { Psychiatric } \\
\text { diagnostics }\end{array}$ \\
\hline He et al. [19] & 58 vs. 1388 & Case-control & NP vs. $\mathrm{Np}$ & 49.5 & Self-rating & SCL-90/STAI \\
\hline $\begin{array}{l}\text { Wang et al. } \\
{[20]}\end{array}$ & 52 vs. 1338 & Case-control & NP vs. Np & $48.25 \pm 13.36$ & Self-rating & SCL-90 \\
\hline Lou et al. [21] & 60 vs. 56 & Case-control & NP vs. HC & $54.31 \pm 8.18$ & Self-rating & SCL-90 \\
\hline Chen et al. [22] & 106 vs. 76 & Case-control & NP vs. HC & $51 \pm 8$ vs. $48 \pm 7$ & $\begin{array}{c}\text { Chinese acknowledged diagnostic } \\
\text { criteria }\end{array}$ & SDS \\
\hline Fang et al. [23] & 89 vs. 60 & Case-control & NP vs. HC & 49.3 vs. 47.6 & Self-rating & SCL-90 \\
\hline Yao et al. [24] & 122 vs. 122 & Case-control & NP vs. HC & $\begin{array}{c}58.86 \pm 8.28 \text { vs. } 59.36 \pm \\
7.04\end{array}$ & Self-rating & $\begin{array}{c}\text { SCL- } \\
\text { 290/SDS/SAS }\end{array}$ \\
\hline $\begin{array}{l}\text { Zhang et al. } \\
\text { [25] }\end{array}$ & 30 vs. 1338 & Case-control & NP vs. Np & 52 & $\begin{array}{c}\text { Chinese acknowledged diagnostic } \\
\text { criteria }\end{array}$ & SCL-90 \\
\hline Wei et al. [26] & 217 vs. 1338 & Case-control & NP vs. Np & $38.00 \pm 5.67$ & Self-rating & SCL-90 \\
\hline $\begin{array}{l}\text { Huang et al. } \\
\text { [27] }\end{array}$ & 38 vs. 1340 & Case-control & NP vs. Np & I & Self-rating & SDS/SAS \\
\hline $\begin{array}{l}\text { Wen and Liu } \\
{[28]}\end{array}$ & 336 vs. 1340 & Case-control & NP vs. Np & I & Self-rating & SDS \\
\hline $\begin{array}{l}\text { Wang et al. } \\
\text { [29] }\end{array}$ & 105 vs. 198 & $\begin{array}{l}\text { Prospective } \\
\text { cohort }\end{array}$ & NP vs. HC & l & $\begin{array}{c}\text { Chinese acknowledged diagnostic } \\
\text { criteria }\end{array}$ & Self-rating \\
\hline Chen et al. [7] & $\begin{array}{l}1026 \text { vs. } 1 \\
338\end{array}$ & Case-control & NP vs. Np & I & Self-rating & SCL-90 \\
\hline Sun et al. [30] & 100 vs. 100 & Case-control & NP vs. HC & $\begin{array}{c}45.98 \pm 8.54 \text { vs } \\
45.86 \pm 8.43\end{array}$ & $\begin{array}{c}\text { Chinese acknowledged diagnostic } \\
\text { criteria }\end{array}$ & $\begin{array}{l}\text { GAD-7/PHQ- } \\
9\end{array}$ \\
\hline
\end{tabular}

NP, neck pain; HC, healthy controls; Np, normal population; SCL, symptom check list; STAI, state-trait anxiety inventory; SDS, self-rating depression scale; SAS, self-rating anxiety scale; GAD-7, generalized anxiety disorder-7; and PHQ-9, patient health questionnaire-9.

TABLE 2: Methodological quality of the case-control studies $(N=12)$.

\begin{tabular}{|c|c|c|c|}
\hline \multirow[b]{2}{*}{ Question } & \multicolumn{3}{|c|}{ Answer } \\
\hline & $\begin{array}{c}\text { Yes } \\
N\end{array}$ & $\begin{array}{c}\text { No } \\
N\end{array}$ & $\begin{array}{c}\text { Unclear } \\
N\end{array}$ \\
\hline \multicolumn{4}{|l|}{ Cases } \\
\hline $\begin{array}{l}\text { Was the clinical setting used for recruitment made } \\
\text { clear? }\end{array}$ & 10 & 1 & 1 \\
\hline $\begin{array}{l}\text { Was the denominator from which cases were } \\
\text { recruited described? }\end{array}$ & 8 & 1 & 3 \\
\hline Was duration of illness adequately described? & 4 & 8 & 0 \\
\hline $\begin{array}{l}\text { Was adequate information given on the total number } \\
\text { of patients approached? }\end{array}$ & 3 & 9 & 0 \\
\hline $\begin{array}{l}\text { Was information given on participants and } \\
\text { nonparticipants? }\end{array}$ & 2 & 10 & 0 \\
\hline $\begin{array}{l}\text { Was information given on the differences between } \\
\text { participants and refusers? }\end{array}$ & 0 & 12 & 0 \\
\hline $\begin{array}{l}\text { Were the inclusion and exclusion criteria described } \\
\text { well enough to be replicable? }\end{array}$ & 10 & 2 & 0 \\
\hline \multicolumn{4}{|l|}{ Controls } \\
\hline $\begin{array}{l}\text { Did the study use controls who were } \\
\text { students/employees of the research institution?* }\end{array}$ & 0 & 11 & 1 \\
\hline $\begin{array}{l}\text { Were controls selected from an explicit sampling } \\
\text { frame? }\end{array}$ & 9 & 2 & 1 \\
\hline Did the study recruit through advertisements?* & 0 & 11 & 1 \\
\hline $\begin{array}{l}\text { Were similar exclusion criteria applied for controls as } \\
\text { for cases? }\end{array}$ & 4 & 0 & 8 \\
\hline $\begin{array}{l}\text { Was information given on number of controls } \\
\text { approached? }\end{array}$ & 6 & 6 & 0 \\
\hline $\begin{array}{l}\text { Was adequate information given on differences } \\
\text { between controls refusing and agreeing? } \\
\text { Information bias }\end{array}$ & 0 & 12 & 0 \\
\hline $\begin{array}{l}\text { Were the investigators who rated the exposure } \\
\text { masked to participants' status? }\end{array}$ & 9 & 3 & 0 \\
\hline
\end{tabular}

* "no" is the answer indicative of good methodological practice. 


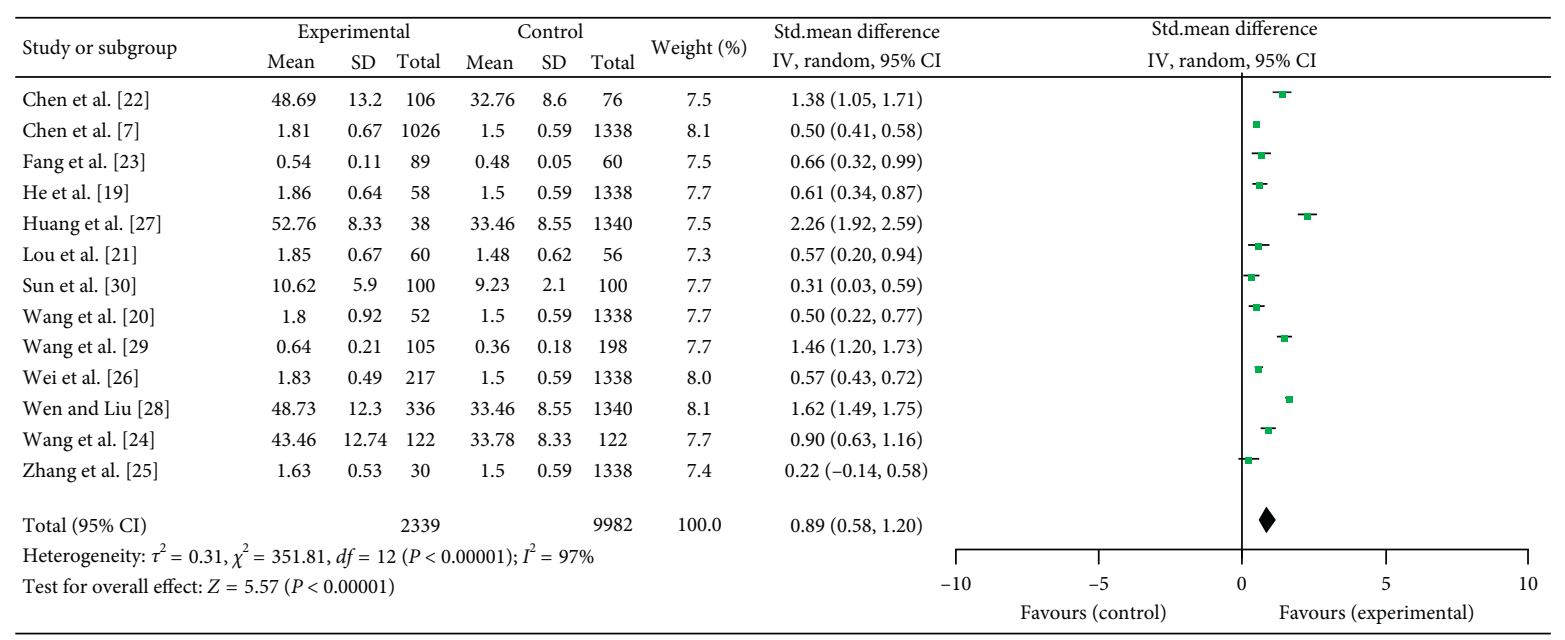

Figure 2: Meta-analysis of 13 studies about depression in NP.

\begin{tabular}{|c|c|c|c|c|c|c|c|c|c|c|c|c|}
\hline \multirow{3}{*}{$\begin{array}{l}\text { Study or subgroup } \\
\text { Chen et al. [7] }\end{array}$} & \multicolumn{3}{|c|}{ Experimental } & \multicolumn{3}{|c|}{ Control } & & \multirow{2}{*}{$\begin{array}{l}\text { Std.mean difference } \\
\text { IV, random, } 95 \% \text { CI }\end{array}$} & \multirow{2}{*}{\multicolumn{4}{|c|}{$\begin{array}{l}\text { Std.mean difference } \\
\text { IV, random, 95\% CI }\end{array}$}} \\
\hline & \multirow{2}{*}{$\begin{array}{c}\text { Mean } \\
1.76\end{array}$} & \multirow{2}{*}{$\frac{\mathrm{SD}}{0.58}$} & \multirow{2}{*}{$\begin{array}{c}\text { Total } \\
1026\end{array}$} & \multirow{2}{*}{$\begin{array}{c}\text { Mean } \\
1.39\end{array}$} & \multirow{2}{*}{$\frac{\mathrm{SD}}{0.43}$} & \multirow{2}{*}{$\begin{array}{c}\text { Total } \\
1338\end{array}$} & & & & & & \\
\hline & & & & & & & $\begin{array}{c}\text { Weight (\%) } \\
11.1\end{array}$ & $0.74(0.65,0.82)$ & & \multicolumn{3}{|c|}{-} \\
\hline Fang et al. [23] & 0.48 & 0.12 & 89 & 0.42 & 0.09 & 60 & 9.6 & $0.55(0.21,0.88)$ & & \multicolumn{3}{|l|}{-} \\
\hline He et al. [19] & 1.8 & 0.68 & 58 & 1.39 & 0.43 & 1338 & 10.1 & $2.60(2.26,2.94)$ & & \multicolumn{3}{|c|}{-} \\
\hline Huang et al. [27] & 51.76 & 8.15 & 38 & 29.78 & 8.46 & 1340 & 9.6 & $0.93(0.66,1.19)$ & & \multicolumn{3}{|c|}{-} \\
\hline Lou et al. [21] & 1.98 & 0.45 & 60 & 1.46 & 0.48 & 56 & 9.1 & $1.11(0.72,1.50)$ & & \multicolumn{3}{|c|}{-} \\
\hline Sun et al. [30] & 9.71 & 5.93 & 100 & 7.89 & 4.01 & 100 & 10.0 & $0.36(0.08,0.64)$ & & \multicolumn{3}{|l|}{-} \\
\hline Wang et al. [20] & 1.73 & 0.83 & 52 & 1.39 & 0.43 & 1338 & 10.0 & $0.75(0.47,1.03)$ & & \multicolumn{3}{|c|}{-} \\
\hline Wei et al. [26] & 1.65 & 0.51 & 217 & 1.39 & 0.43 & 1338 & 10.9 & $0.59(0.44,0.73)$ & & \multicolumn{3}{|l|}{ - } \\
\hline Wang et al. [24] & 42.24 & 10.38 & 122 & 32.26 & 8.36 & 122 & 10.1 & $1.06(0.79,1.32)$ & & \multicolumn{3}{|c|}{-} \\
\hline Zhang et al. [25] & 1.67 & 0.59 & 30 & 1.39 & 0.43 & 1338 & 9.4 & $0.64(0.28,1.01)$ & & \multicolumn{3}{|c|}{-} \\
\hline \multicolumn{3}{|l|}{ Total $(95 \% \mathrm{CI})$} & 1792 & & & 8368 & 100.0 & $0.92(0.65,1.20)$ & & \multicolumn{3}{|c|}{$\bullet$} \\
\hline Heterogeneity: $\tau^{2}=$ & $=138.9$ & $d f=9$ & $(P<0$ & $00001) ;$ & $I^{2}=949$ & & & $\Gamma$ & $T$ & & $T$ & \\
\hline Test for overall effe & $.54(P<$ & 0.00001 & & & & & & -10 & -5 & 0 & 5 & \\
\hline & & & & & & & & & Favours (control) & & Favours (expe & imental) \\
\hline
\end{tabular}

FIgURE 3: Meta-analysis of 10 studies about anxiety in NP patients.

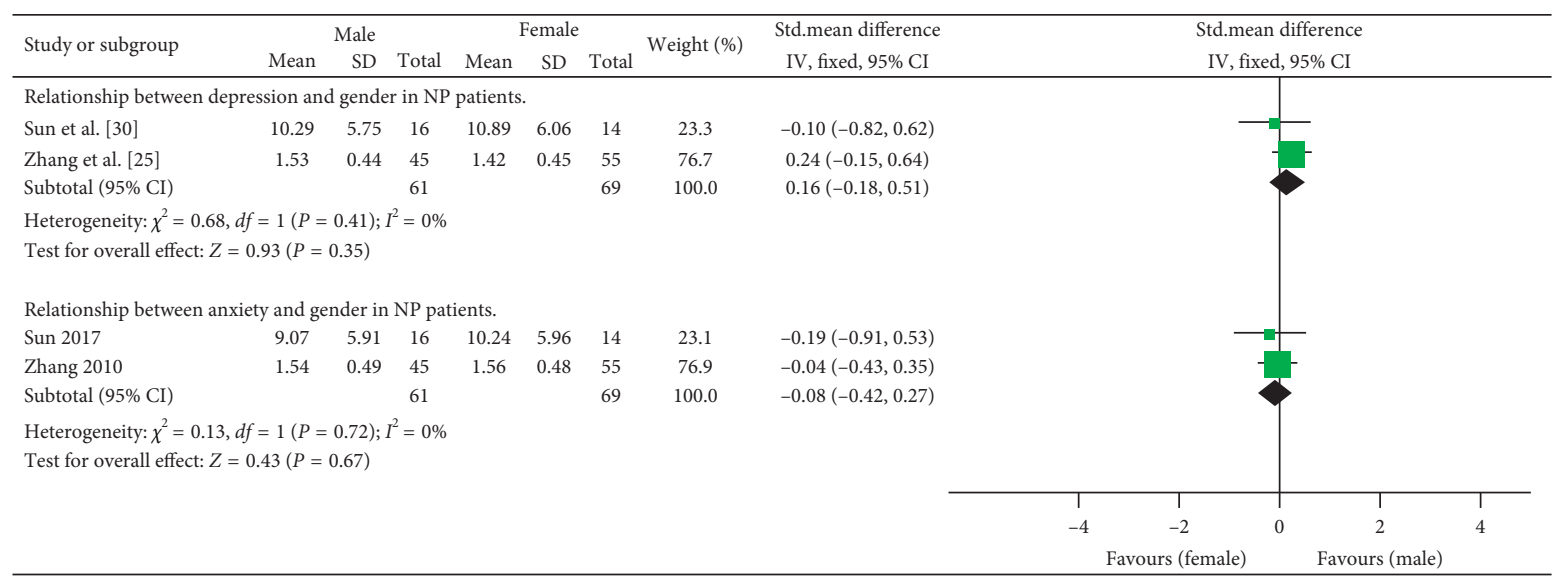

FIGURE 4: Relationship between depression/anxiety and gender in NP patients.

that changed from the insula topology to the prefrontal area of weight-bearing pain management [35]. Besides, it was also found patients with depression and anxiety symptoms had dysfunction of autonomic nervous function and inflammation and activity hyperactivity of the hypothalamicpituitary-adrenal (HPA) axis [38-41]. Interestingly, when neurotransmitters such as norepinephrine (NE) and 5-hydroxytryptamine (5-HT) decrease, the inhibitory mechanism of pain can be impeded and the development of affective disorders can be promoted [42]. Additionally, studies found an increase in systemic inflammatory markers in the blood of patients with pain disorders and affective 


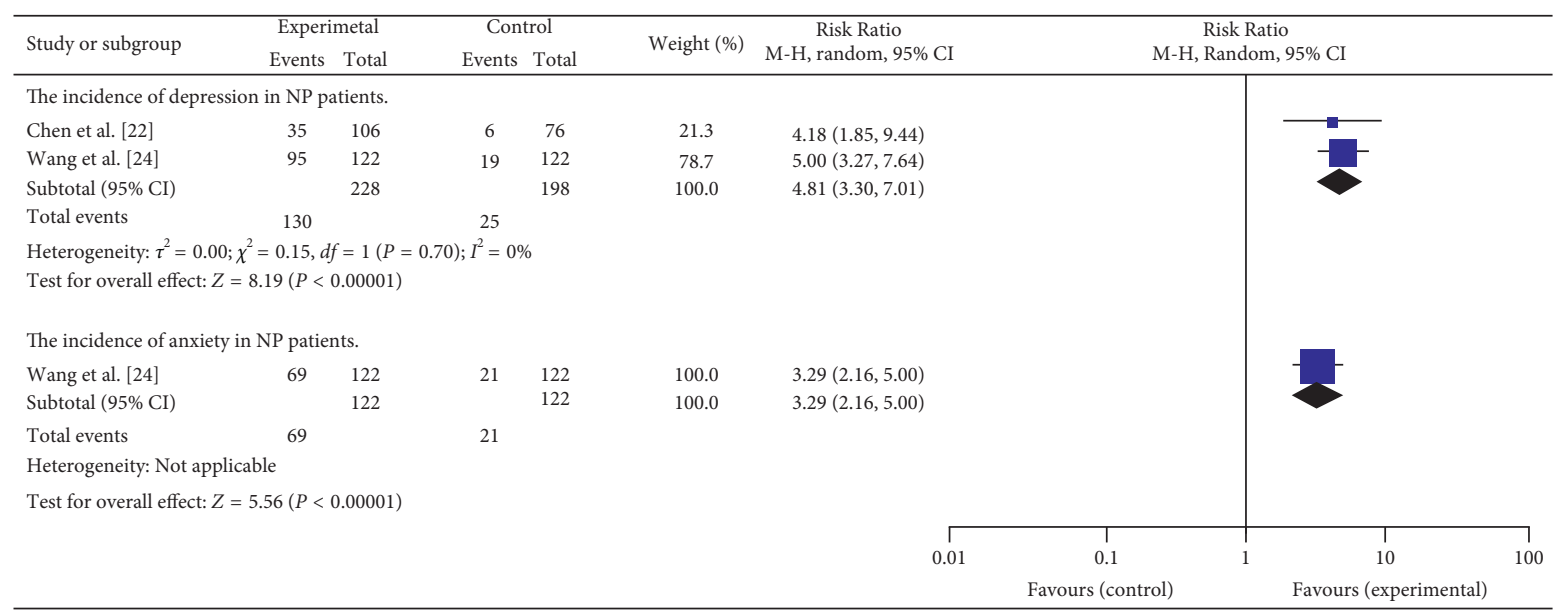

FIgURE 5: The incidence of depression/anxiety in NP patients.

disturbances, which suggests that there is the same basic pathogenetic pathway between the two diseases [43-45]. Similarly, consideration from the view of psychological sociology, pain, and mental disorders are also closely related. Many studies point out that psychological stress and potential obstacles caused by pain can possibly cause immunological changes that eventually results in depression and anxiety [40, 45-47]. In addition, a study had shown that both depression and pain might be risk factors for each other [48].

Anyhow, we should notice potential restrictions of this article. It included first that although we assessed the methodological quality of the included studies via a rating scale [18] for case-control studies, we cannot declare that the rating scale is valid even if the score presented high credibility. Second, few studies provided categorical data, despite 5 studies [22, 24, 27, 28, 30] had involved it, and none of them provided complete data except 2 [22, 24]. The incomplete data may not draw definite conclusion. Furthermore, there were no uniform inclusion and exclusion criteria, which may be a source of heterogeneity.

Despite these limitations, there are still many advantages in our study. In order to improve the accountability of the systematic procedure of this systematic review, we had taken several steps. Two reviewers (Ting Fang and Mei Chen) conducted the electronic searches and picked the suitable studies after browsing the abstracts and full-text articles, respectively, according to the inclusion criteria. Data extraction was also completed, respectively, by two authors. And the methodological quality of the included studies was still evaluated by two authors, and the results were counted.

\section{Conclusions}

Overall, NP is characterized as a kind of chronic degenerative disease, which has a series of serious influences on body and psychology and severely reduces the quality of life of patients. Therefore, attention should be cautiously attached to the psychological problems in the treatment of NP patients. And clinicians should give the necessary psychological counseling and psychological treatment, which may help alleviate the mental pain of patients and relieve their physical pain at the same time. Moreover, clinicians who treat pain syndromes should not only improve the patients' correct understanding of disease and treatment but also strengthen patients' confidence to overcome the disease.

\section{Conflicts of Interest}

The authors declare that they have no conflicts of interest.

\section{Authors' Contributions}

All authors made substantial contributions to the conception and design of the work, acquisition, analysis, or interpretation of the data, drafting of the manuscript, and/or critical revision for important intellectual content. All authors approved the final version of the manuscript accepted for publication and agree to be accountable for the integrity of all aspects of the work.

\section{Acknowledgments}

This study was supported by grants from the National Natural Science Foundation of China (81560792).

\section{References}

[1] M. Vassilaki and E. L. Hurwitz, "Insights in public health: perspectives on pain in the low back and neck: global burden, epidemiology, and management," Hawaii Journal of Medicine \& Public Health, vol. 73, no. 4, pp. 122-126, 2014.

[2] D. Hoy, L. March, A. Woolf et al., "The global burden of neck pain: estimates from the global burden of disease 2010 study," Annals of the Rheumatic Diseases, vol. 73, no. 7, pp. 13091315, 2014.

[3] E. L. Hurwitz, L. Dongmei, G. Jenni et al., "Variations in patterns of utilization and charges for the care of neck pain in North Carolina, 2000 to 2009: a statewide claims' data analysis," Journal of Manipulative and Physiological Therapeutics, vol. 39, no. 4, pp. 240-251, 2016.

[4] E. L. Hurwitz, K. Randhawa, H. Yu, P. Côté, and S. Haldeman, "The Global Spine Care Initiative: a summary of the global 
burden of low back and neck pain studies," European Spine Journal, 2018.

[5] Disease and Injury Incidence and Prevalence Collaborators, "Global, regional, and national incidence, prevalence, and years lived with disability for 310 diseases and injuries, 1990-2015: a systematic analysis for the Global Burden of Disease Study 2015," The Lancet, vol. 388, no. 10053, pp. 1545-1602, 2016.

[6] S. Kang, A Full Strategy for the Rescue of Cervical Spondylosis, Jilin Science and Technology Press, Changchun, China, 2008.

[7] X. Chen, C. L. Ma, and Y. R. Xue, "Study on preoperative mental health level of patients with cervical spondylosis," Journal of Qilu Nursing, vol. 23, no. 6, pp. 48-50, 2017.

[8] M. Su, "Basic research and progress in acupuncture and moxibustion treatment of neck type cervical spondylosis," Guide of China Medicine, vol. 14, no. 23, pp. 34-36, 2016.

[9] M. D. Connell and S. W. Wiesel, "Natural history and pathogenesis of cervical disk disease," Orthopedic Clinics of North America, vol. 23, no. 3, pp. 369-380, 1992.

[10] L. Lu, "Clinical study on dose-effect of elaborate-moxibustion on neck pain in cervical spondylosis," M. S. thesis, Guangzhou university of Chinese medicine, Guangzhou, China, 2017.

[11] V.S. H. Madhavee, "Western and Chinese medicine approach on treatment of cervical spondylosis," M. S. thesis, Beijing university of Chinese medicine, Beijing, China, 2017.

[12] J. S. Olver and M. J. Hopwood, "Depression and physical illness," Medical Journal of Australia, vol. 199, no. 6, pp. S9-12, 2013.

[13] W. Katon, E. H. Lin, and K. Kroenke, "The association of depression and anxiety with medical symptom burden in patients with chronic medical illness," General Hospital Psychiatry, vol. 29, no. 2, pp. 147-155, 2007.

[14] A. Tsang, M. Von Korff, S. Lee S et al., "Common chronic pain conditions in developed and developing countries: gender and age differences and comorbidity with depression-anxiety disorders," Journal of Pain, vol. 9, no. 10, pp. 883-891, 2008.

[15] Z. Dimitriadis, E. Kapreli, N. Strimpakos et al., "Do psychological states associate with pain and disability in chronic neck pain patients?," Journal of Back and Musculoskeletal Rehabilitation, vol. 28, no. 4, pp. 797-802, 2015.

[16] F. Kayhan, İ. A. Gezer, A. Kayhan, S. Kitiş, and M. Gölen, "Mood and anxiety disorders in patients with chronic low back and neck pain caused by disc herniation," International Journal of Psychiatry in Clinical Practice, vol. 20, no. 1, pp. 19-23, 2016.

[17] A. Liberati, D. G. Kltman, J. Tetzlaff et al., "The PRISMA statement for reporting systematic reviews and meta-analyses of studies that evaluate health care interventions: explanation and elaboration," Annals of Internal Medicine, vol. 151, no. 4, pp. W65-W94, 2009.

[18] L. William, B. Jonathan, F. Tamsin et al., "Bias in psychiatric case-control studies: literature survey," British Journal of Psychiatry, vol. 190, pp. 204-209, 2007.

[19] X. He, J. H. Lin, and J. Hong, "Analysis of sleep quality and mental health status of patients with cervical spondylosis," Chinese Journal of Clinical Rehabilitation, vol. 6, no. 16, pp. 2428-2429, 2002.

[20] H. L. Wang, Y. M. Lou, and R. Xue, "Psychological analysis of 52 patients with cervical spondylosis," Journal of Henan University of Science \& Technology: Medical Science, vol. 21, no. 3, pp. 187-188, 2003.

[21] Y. M. Lou, S. H. Han, and J. H. Guo, "Analysis of mental health status and quality of life of patients with cervical spondylosis," Journal of Traditional Chinese Orthopedics and Traumatology, vol. 18, no. 11, pp. 15-16, 2006.

[22] C. L. Chen, Y. Wang, and G. P. He, "Study on depressive disorders of cervical spondylosis," Shanghai Archives of Psychiatry, vol. 19, no. 2, pp. 106-107, 2007.

[23] Z. Fang, F. Li, Q. Yang et al., "Study of the psychological and social factors in patients with cervical spondylotic myelopathy," China Journal of Modern Medicine, vol. 17, no. 5, pp. 583-585, 2007.

[24] X. Yao, K. Yao, J. J. Fan et al., "Research on the incidence of depression \& anxiety of patients with cervical spondylopathy and psychological \& ethical intervention," Chinese Medical Ethics, vol. 23, no. 5, pp. 61-62, 2010.

[25] D. J. Zhang, T. X. Cheng, J. G. Wang et al., "Investigation and analysis on the mental health status of 30 patients with cervical spondylosis," China Journal of Health Psychology, vol. 18, no. 2, pp. 149-150, 2010.

[26] J. Wei, P. Zhao, L. J. Chen et al., "Influence of social support and personality traits on psychological characteristic of patients with chronic cervicodynia and lumbodynia," Chinese Journal of Traumatology, vol. 25, no. 3, pp. 216-219, 2012.

[27] C. L. Huang, Q. M. Lu, L. X. Huang et al., "Investigation and analysis of relationship among medical uncertainty, anxiety and depression of cervical spondylosis patients," China Medical Herald, vol. 10, no. 9, pp. 109-113, 2013.

[28] J. Wen and M. J. Liu, "Investigation research and nursing measures on depression and social supports for cervical spondylosis patients," Nursing Practice and Research, vol. 10, no. 3, pp. 6-9, 2013.

[29] C. L. Wang, C. M. Yang, J. Y. Yun et al., "Investigation and analysis of related factors of 330 college students' sub-health cervical spine," Journal of Liaoning Medical University, vol. 35, no. 5, pp. 71-73, 2014.

[30] Z. X. Sun, Y. X. Sun, and X. F. Yu, "Correlative analysis of the quality of sleep and anxiety and depression in patients with cervical spondylosis," Journal of Shandong Medical College, vol. 39, no. 3, pp. 161-165, 2017.

[31] F. Altug, E. Kavlak, M. P. Kurtca et al., "Comparison of pain intensity, emotional status and disability level in patients with chronic neck and low back pain," Journal of Back and Musculoskeletal Rehabilitation, vol. 28, no. 3, pp. 505-508, 2015.

[32] M. Soysal, B. Kara, and M. N. Arda, "Assessment of physical activity in patients with chronic low back or neck pain," Turk Neurosurgery, vol. 23, no. 1, pp. 75-80, 2013.

[33] A. Y. Q. Xiao and Z. P. Hu, "Joint anti-anxiety treatment clinical observation in patients with cervical spondylosis anxiety," Journal of Medical Practice Management, vol. 28, no. 8, pp. 993-994, 2015.

[34] G. L. Chen, M. Wang, G. J. Lu et al., "Investigation of anxiety and depression in chronic pain patients and analysis of related factors," China Journal of Pain Medicine, vol. 20, no. 4, pp. 226-230, 2014.

[35] X. Y. Chen, "Clinical observation on 30 cases of cervical spondylosis with anxiety treated by Zhen-fu Tuina," M. S. thesis, Beijing University of Chinese Medicine, Beijing, China, 2017.

[36] F. Galbusera, M. van Rijsbergen, K. Ito et al., "Ageing and degenerative changes of the intervertebral disc and their impact on spinal flexibility," European Spine Journal, vol. 23, no. 3, pp. S324-S332, 2014.

[37] K. Gorter, "Influence of laminectomy on the course of cervical myelopathy," Acta Neurochirurgica, vol. 33, no. 3-4, pp. 265-281, 1976. 
[38] S. A. Vreeburg, W. J. Hoogendijk, J. van Pelt et al., "Major depressive disorder and hypothalamic-pituitary-adrenal axis activity: results from a large cohort study," Archives of General Psychiatry, vol. 66, no. 6, pp. 617-626, 2009.

[39] M. J. Bair, R. L. Robinson, W. Katon et al., "Depression and pain comorbidity: a literature review," Archives of Internal Medicine, vol. 163, no. 20, pp. 2433-2445, 2003.

[40] D. A. Fishbain, R. Cutler, H. L. Rosomoff et al., "Chronic painassociated depression pressure: antecedent or consequence of chronic pain? A review," Clinical Journal of Pain, vol. 13, no. 2, pp. 116-137, 1997.

[41] M. R. Andrew, "What works for whom? Determining the efficacy and harm of treatments for pain," Pain, vol. 154, no. 1, pp. S77-S86, 2013.

[42] J. Dersh, P. B. Polatin, and R. J. Gatchel, "Chronic pain and psychopathology: research findings and theoretical considerations," Psychosomatic Medicine, vol. 64, no. 5, pp. 773-786, 2002.

[43] Y. Sun and G. C. Li, "Summary of the second symposium on cervical spondylosis," Chinese Journal of Surgery, vol. 31, no. 8, pp. 472-476, 1993.

[44] Y. F. Liu and B. Y. Wang, "The significance of X-ray examination in the diagnosis of cervical spondylosis-appending clinical analysis of 158 cases," Journal of Traditional Chinese Orthopedics and Traumatology, vol. 19, no. 3, pp. 17-19, 2007.

[45] N. Vogelzangs, A. T. F. Beekman, P. de Jonge, and B. W. J. H. Penninx, "Anxiety disorders and inflammation in a large adult cohort," Translational Psychiatry, vol. 3, no. 4, p. e249, 2013.

[46] P. C. Ren, "Comparative study on the application of X-ray, CT and MRI in the diagnosis of cervical spondylosis," China Medicine and Pharmacy, vol. 3, no. 24, pp. 113-114, 2013.

[47] D. E. Battle, "Diagnostic and statistical manual of mental disorders (DSM)," Codas, vol. 25, no. 2, pp. 191-192, 2013.

[48] P. Zis, A. Daskalaki, I. Bountouni et al., "Depression and chronic pain in the elderly: links and management challenges," Clinical Interventions in Aging, vol. 12, pp. 709-720, 2017. 


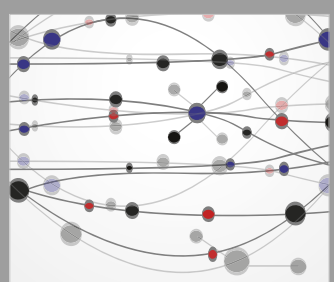

The Scientific World Journal
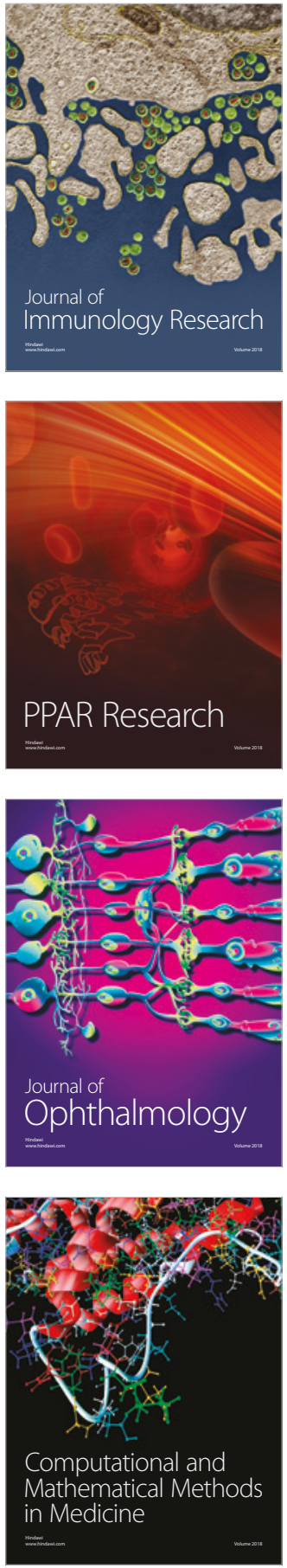

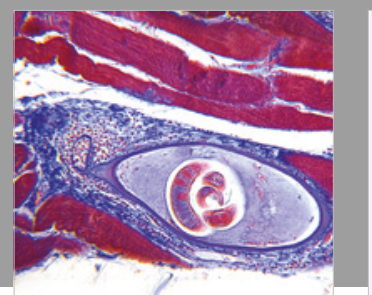

Gastroenterology Research and Practice

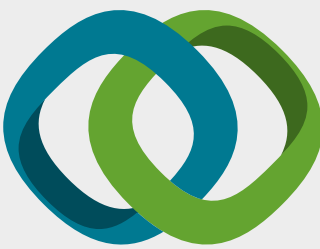

\section{Hindawi}

Submit your manuscripts at

www.hindawi.com
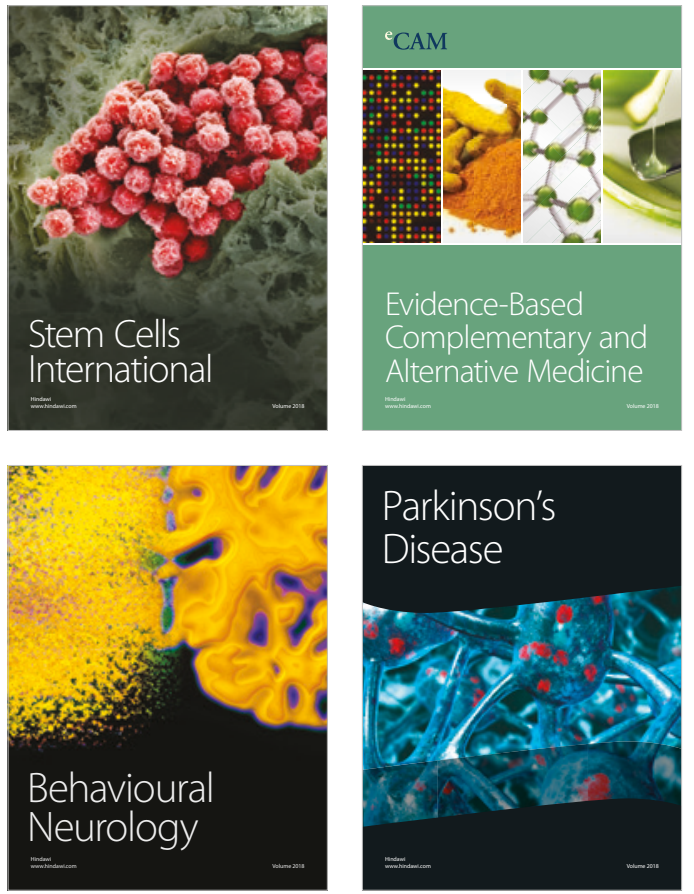

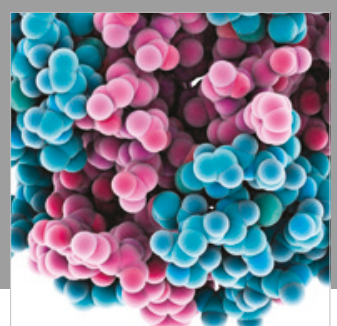

ournal of

Diabetes Research

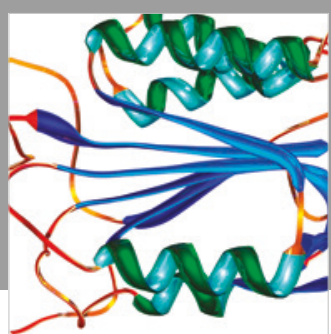

Disease Markers
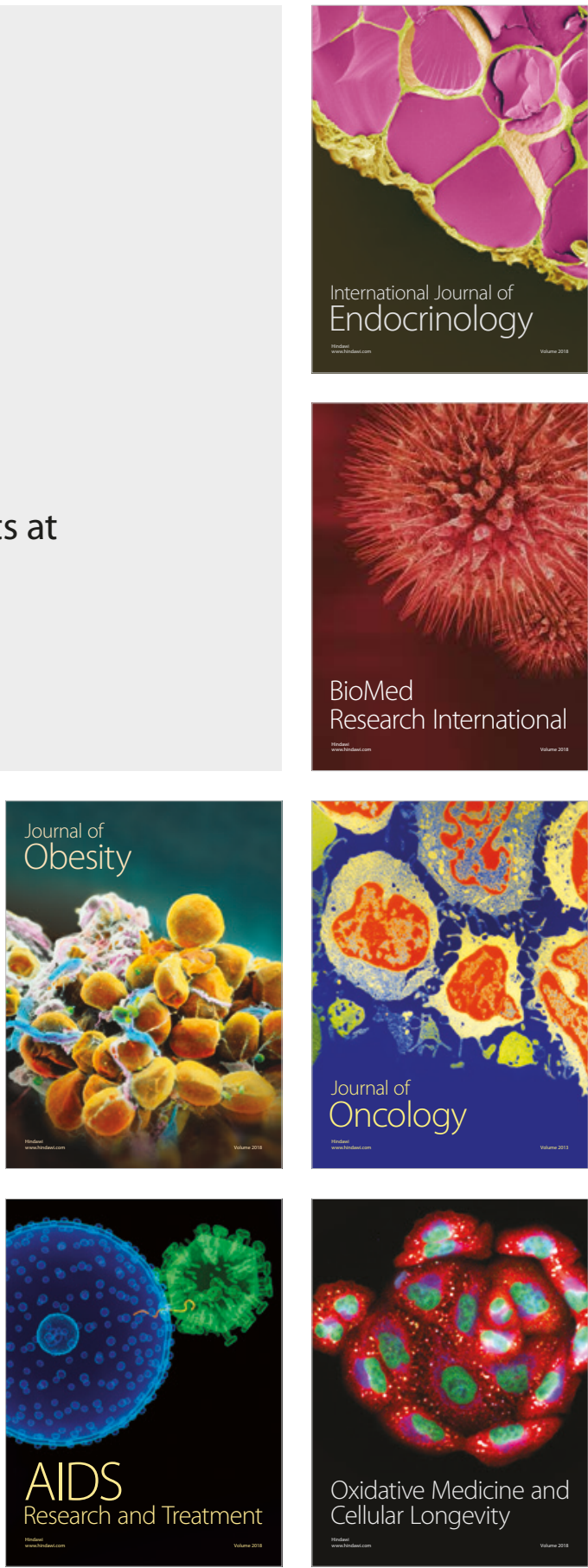